Res., Soc. Dev. 2019; 8(1):e4281674

ISSN 2525-3409 | DOI: http://dx.doi.org/10.33448/rsd-v8i1.674

\title{
A História e Filosofia da Ciência como subsídio para uma estratégia didática sobre
} radioatividade

The History and Philosophy of Science as a subsidy for a didactic strategy on radioactivity

La Historia y Filosofía de la Ciencia como subsidio para una estrategia didáctica sobre radioactividad

\section{Lucas Peres Guimarães}

ORCID: https://orcid.org/0000-0003-1648-2019

Prefeitura Municipal de Volta Redonda, Brasil

E-mail: lucaspegui@hotmail.com.br

Denise Leal de Castro

ORCID: https://orcid.org/0000-0003-4572-4689

Instituto Federal de Educação, Ciência e tecnologia do Rio de Janeiro, Brasil

E-mail: denise.castro@ifrj.edu.br

Recebido: 11/10/2018 | Revisado: 18/10/2018 | Aceito: 07/11/2018 | Publicado: 14/11/2018

\section{Resumo}

Este trabalho busca relatar uma sequência didática para o tema da radioatividade através da História da Ciência que tem como objetivo a inserção de discussões sociais como a mulher na ciência e a construção do conhecimento científico. As estratégias utilizadas foram: roda de conversa, análise de textos, experimentação e debate. A intervenção busca tratar dos estudos envolvendo a radioatividade e o contexto histórico do período entre Henri Becquerel e Marie Curie. O principal objetivo é mostrar aos alunos que a ciência não está pronta pois se constrói coletivamente. As questões respondidas pelos educandos apontam um melhor entendimento do trabalho do cientista, não o considerando socialmente neutro e alheio ao mundo. Os resultados mostraram que os conhecimentos científicos foram assimilados de forma gradativa e que as metodologias utilizadas propiciaram uma interlocução de saberes.

Palavras-chave: Marie Curie; Ensino de Química; Radioatividade

\section{Abstract}

This work aims to report a didactic sequence for the theme of radioactivity through the History of Science. The strategies used were conversation wheel, analysis of texts, experimentation and debates. 
The intervention seeks to address the studies involving radioactivity and the historical context of the period between Henri Becquerel and Marie Curie. The main objective is to show students that science is not ready because it is built collectively. The questions answered by the students point to a better understanding of the scientist's work, not considering it socially neutral and random to the world. The results showed that scientific knowledge was assimilated gradually and that the methods used have led to a dialogue of knowledge.

Keywords: Marie Curie; Chemistry teaching; Radioactivity

\section{Resumen}

Este trabajo busca relatar una secuencia didáctica para el tema de la radioactividad a través de la Historia de la Ciencia que tiene como objetivo la inserción de discusiones sociales como la mujer en la ciencia y la construcción del conocimiento científico. Las estrategias utilizadas fueron: rueda de conversación, análisis de textos, experimentación y debate. La intervención busca tratar los estudios involucrando la radioactividad y el contexto histórico del período entre Henri Becquerel y Marie Curie. El principal objetivo es mostrar a los alumnos que la ciencia no está lista pues se construye colectivamente. Las cuestiones respondidas por los educandos apuntan un mejor entendimiento del trabajo del científico, no el considerando socialmente neutro y ajeno al mundo. Los resultados mostraron que los conocimientos científicos fueron asimilados de forma gradual y que las metodologías utilizadas propiciaron una interlocución de saberes.

Palabras clave: Marie Curie; Enseñanza de Química; radioactividad

\section{Introdução}

Muitas são as pesquisas abordando possibilidades para facilitar a aprendizagem da Química. Mas poucas buscam a intersecção das descobertas científicas com o momento social e histórico em que elas aconteceram. Acreditamos que o uso da História da Ciência em sala de aula possa fornecer muitas contribuições para o processo de ensino/aprendizagem dessa disciplina. Podemos afirmar que além de contextualizar o ensino de ciências, analisar a história pode fornecer aos estudantes uma oportunidade de aprender a questionar e buscar a melhor compreensão dos processos sociais, econômicos e culturais passados e contemporâneos (BRASIL, 2006).

Neste sentido, esse trabalho propõe uma estratégia didática para trabalhar um "recorte" histórico do tema radioatividade através da História da Química. Sabe-se que esse assunto, 
também, é abordado em Física, entretanto, priorizaremos a concepção do trabalho do cientista que os educandos possuem.

Os textos propostos nessa intervenção didática visam trabalhar algumas concepções alternativas dos alunos sobre o trabalho do cientista, como por exemplo, a Química como uma Ciência pronta ou como verdade absoluta, a questão dos pioneiros ou do pai (pai da Química, pai da Física), ênfase nos ditos vencedores, se esquecendo todo o processo que ocorria na época.

A análise de um recorte histórico de Becquerel até Marie Curie foi além da expectativa, pois a partir dos depoimentos obtidos nas atividades, ficou claro para os alunos a importância do trabalho dos cientistas. A partir do suposto "fracasso" de Becquerel é que Marie Curie iniciou seus estudos até a descoberta da radioatividade, ou seja, foi fundamental que os alunos percebessem a importância do "fracasso", pois sem os trabalhos dele talvez Marie Curie não tivesse a oportunidade de se interessar pelo assunto.

\section{A importância de estratégias didáticas envolvendo a história da ciência}

Dentre as possibilidades no ensino de ciências, esse trabalho utilizará o uso crítico da História da Ciência essa é uma vertente que permite ao aluno a percepção da construção do conhecimento e do progresso da ciência (PEDUZZI, 2005). Nesse sentido, procura-se um ensino de ciências que vise diminuir a fragmentação de conteúdo e conhecimento que são dados em sala de aula, fato constantemente encontrado, inserindo-a num contexto de maior amplitude.

Martins (2001), reforça que o ensino da História e da Filosofia da Ciência, vêm se tornando objeto de inúmeras pesquisas por parte de historiadores, filósofos e educadores em ciência, as quais, quase sempre, culminam em dissertações de mestrado e teses de doutorado. Contudo, como relata Silva (2010), os resultados de intervenções didáticas com a História e Filosofia da Ciência em sala de aula ainda são escassos.

Silva (2010) e Forato (2009), apontam que construir estratégias didáticas valendo-se de elementos da História e Filosofia da Ciência não é algo fácil. O professor que está no processo de construção de tais estratégias pode recorrer a textos da História da Ciência anacrônicas e distorcidas, passando uma visão totalmente equivocada. Por isso, é de suma importante que o educador não somente consiga reconhecer um bom texto histórico, mas também detenha os procedimentos e métodos de aplicação, que nesse caso é o mais 
importante para diferenciar o ensino, enxergando as suas potencialidades e dificuldades de aplicá-lo em sala de aula.

Daniel Gil Pérez e colaboradores (2001) escreveram um artigo denominado "Por uma imagem não deformada do trabalho científico", em que elencam sete visões deformadas presentes a partir do estudo feito com professores e análise de uma extensa literatura. Dentre as visões que foram colocadas pelos autores, esse trabalho irá se preocupar com a visão "aproblemática" e "ahistórica", segundo esse mesmo artigo, essa visão passa uma mensagem dogmática e fechada: transmitem o conhecimento de forma já elaborada sem mostrar os problemas que lhe deram origem, qual foi sua evolução, suas dificuldades. Perde-se assim de vista que todo conhecimento é a resposta de uma pergunta. Assim, essa estratégia didática terá como objetivo uma sequência de atividades que evidenciem ao aluno que o trabalho do cientista está inserido em um contexto social e esse, influencia diretamente na sua pesquisa. Utilizaremos um recorte histórico do desenvolvimento da radioatividade abordando principalmente Henri Becquerel e Marie Curie, muito baseada na abordagem que Ediana Barp fez em seu artigo "Contribuições da História da Ciência para o Ensino da Química: Uma Proposta para Trabalhar o Tópico Radioatividade".

Assim, se buscamos uma mudança nas salas de aula, onde os alunos não construam apenas conhecimentos científicos desordenados e sem nenhum sentido para seu cotidiano, mas que discutam várias dimensões cognitivas e intelectuais, técnicas, pessoais e sociais da atividade científica, novas práticas, nessa direção, devem ser pensadas e aplicadas.

\section{Metodologia}

Este trabalho foi realizado em uma escola municipal da cidade de Volta Redonda, no Sul Fluminense (RJ). A turma pertence ao $3^{\circ}$ Ciclo da modalidade da Educação de Jovens e Adultos (EJA), o que compreende o $6^{\circ}$ e $7^{\circ}$ ano do ensino fundamental, do turno noturno. No total, participaram das intervenções didáticas, 15 alunos, entre 15 e 58 anos. Foi utilizado o método qualitativo que segundo Lakatos e Marconi (2010), é utilizado quando percepções e entendimentos são buscados sobre a natureza geral de uma questão e o espaço para interpretação é aberto. Foram utilizadas três técnicas de coleta de dados ou materiais: a observação livre, feita nas aulas, o conjunto de questões e o diário de bordo. Para que as intervenções didáticas sejam compreendidas, torna-se necessário organizar as atividades que foram realizadas em sala de aula:

A sequência didática foi fundamentada nos seguintes eixos: (1) a realização de uma roda de conversa, que tinha por finalidade mapear algumas concepções alternativas dos alunos 
sobre o assunto a ser estudado, no caso, a concepção do trabalho científico, (2) o trabalho com os textos históricos, (3) um debate em sala de aula, que chamamos de "diálogo" entre os dois textos e todas essas atividades continham uma atividade final com o objetivo de avaliar a aprendizagem.

O primeiro encontro, que teve duração de 3 horas, foi uma roda de conversa, nesta, procurou-se investigar o que aluno sabe sobre a radioatividade, através de questionamentos como: Onde aparecem os fenômenos relacionados à radioatividade e o que vem a ser esse fenômeno? A radioatividade é uma coisa boa ou ruim? Quem descobriu a radioatividade?

$\mathrm{Na}$ roda de conversa os dados foram coletados a partir do diário de bordo e no dia seguinte foi proposto que os alunos utilizassem os computadores e os livros presentes na escola para que as perguntas feitas fossem respondidas com mais conhecimento.

No segundo encontro, foi extraído e adaptado um texto do livro "Química em Questão" (MATHEUS, 2012). O texto teve como título: "Radioatividade: explorações do invisível", essa atividade teve como principal objetivo informar aos alunos que a radioatividade é um fenômeno natural e que está em muitas ocasiões no nosso cotidiano, e que nem sequer percebemos.

No terceiro encontro, com duração de 2 horas, foi realizado o experimento sobre fluorescência e fosforescência com materiais alternativos, proposto no livro "Química em Questão" (MATHEUS, 2012), com o objetivo levar ao aluno a sensação da emissão radioativa da maioria dos elementos químicos, já que muitos associam a radiação com brilho e serão ali realizadas algumas atividades com um viés investigativo para que o aluno comece a perceber que tinha uma visão distorcida da radioatividade.

A partir do terceiro encontro, foram utilizados dois textos: um do historiador da física, Professor Roberto Andrade Martins, que trata da descoberta da radioatividade e do contexto histórico do período em que viveu Marie Curie. Os alunos conheceram um pouco sobre Marie Curie, as dificuldades na época de sua pesquisa, e no que diz respeito ao avanço da radioatividade. O segundo texto está disponível no livro "As cientistas: 50 mulheres que mudaram o mundo" de Rachel Ignotofsky, que aborda a contribuição das mulheres no mundo da ciência. Também foram utilizados esses dois textos na última aula, já que esses foram preparados para um complementar o outro e dar a ideia de que a ciência é uma construção humana e coletiva.

Seguindo a estratégia de Silva (2011) em que primeiro ocorre a pré-leitura nesse momento os alunos, com os textos em mão, realizaram uma leitura inicial, e fizeram um 
resumo. Nesse resumo, era comum o aluno apontar tanto dúvidas sobre o conteúdo estudado quanto dificuldades de leitura relacionadas aos termos do texto histórico. Em sala de aula, foi disponibilizado o tempo de uma aula, aproximadamente de 2 horas, para os alunos lerem novamente os textos e discutirem entre si sobre o episódio histórico estudado, mas dessa vez, em duplas. Novamente os alunos fizeram um resumo.Na última etapa de leitura dos textos, agora com as questões, os alunos tinham mais uma aula para resolverem as questões. No fechamento, foram realizadas pelo professor discussões sobre temas relevantes e dúvidas observadas pelos alunos nos textos estudados.

\section{Resultados e Discussão}

O professor da turma, e também, responsável pela pesquisa, realizou as anotações de todas as falas registradas durante os encontros em sala de aula. Para este artigo foram escolhidos apenas os resultados encontrados com o uso de três questões aplicados após os textos escolhidos. Este recurso, segundo Gil (1999, p.128), pode ser definido como "a técnica de investigação composta por um número mais ou menos elevado de questões apresentadas por escrito às pessoas, tendo por objetivo o conhecimento de opiniões, crenças, sentimentos, interesses, expectativas, situações vivenciadas etc."

Com a aplicação das questões iniciais, na roda de conversa, percebeu-se que os alunos, ao explicarem o trabalho do cientista, apresentaram poucas respostas que mostravam a ciência como algo distante da sua vida em sociedade e o cientista como sendo um profissional preso a uma bancada de laboratório. Através dos relatos iniciais obtidos nas rodas de conversa, os estudantes reconheceram que até os cientistas tendem a detectar o que foi anteriormente previsto e, por vezes, deixam de lado aquilo que vai contra sua previsão inicial.

A pretensão inicial desse trabalho, era apenas que o aluno apreendesse o real papel do trabalho do cientista, abandonasse a visão deformada de Ciência “aproblemática" e "ahistórica", que está pronta e acabada e que a experimentação serve apenas para fins de comprovação. Sob este aspecto, observamos uma grande receptividade do trabalho por parte dos alunos.

Após a leitura do primeiro texto (adaptado de MATHEUS, 2012), foi feito com os alunos um experimento mostrando a diferença entre a fosforescência e a fluorescência, para exemplificar o que lemos e para isso, foi utilizado um adesivo fosforescente e os alunos observaram sua luminescência no escuro. Também foi levado para a sala de aula uma lâmpada de luz negra, sabão em pó e uma nota de 5 reais mais nova para ser iluminada e observar o fenômeno de fluorescência. 
Durante o experimento da fluorescência, os alunos perceberam que o sabão em pó brilhava de uma forma diferente, mas também alguns deles observaram que a roupa branca brilhava, mostrando assim que nem tudo que é fluorescente e fosforescente seria radioativo e esse fenômeno não pode ser relacionado tão somente ao brilho de alguns materiais radioativos. Depois do trabalho com os textos, foi realizado um questionamento sobre a fluorescência e a fosforescência relacionando esse brilho com ponteiros de um relógio que brilha no escuro, e foi constatado assim que a maioria dos alunos conseguiu assimilar a diferença entre esses dois conceitos.

Com relação ao principal objetivo do trabalho, no que diz respeito a ciência como construção humana e coletiva, podemos considerar que $70 \%$ dos alunos conseguiram apreender a ciência como uma atividade humana que está sempre em construção.

A seguir são citadas algumas respostas quando perguntados sobre a questão do texto que dizia:

"O volume de trabalhos sobre o assunto naquele período era muito grande. Dessa forma, poderíamos atribuir a descoberta da radioatividade a Becquerel?":

Aluno 1:"Ele fez muitas modificações nas descobertas de outros cientistas, sem ter estudado a descoberta de outros, não teria conseguido";

Aluno 8: "Não foi somente ele que descobriu a radioatividade e sim vários outros cientistas"; Aluno 7:" (...) muitos outros cientistas já estavam estudando";

Aluno 12:"(...)porque era um assunto que já havia anos de estudos por outros cientistas."

Em outro questionamento sobre as diferenças dos trabalhos de Marie Curie e Becquerel, $85 \%$ dos estudantes reconheceram que a ciência se faz a partir de um trabalho coletivo:

Aluno 7"(...)foi adiante";

Aluno 3"(...)ela foi mais a fundo(...)";

Aluno 4" (...)examinou esses exemplos brilhantes bem mais a fundo(...)".

O texto que foi trabalhado em sala de como Becquerel não descobriu a radioatividade foi muito mais além do que inicialmente foi planejado, a partir das respostas obtidas nas questões, e no diálogo desenvolvido entre os textos. No último momento, ficou claro para os alunos a importância do suposto "fracasso" dos trabalhos de Becquerel, pois a partir deles é 
que Marie Curie iniciou seus estudos para assim "alcunhar" o termo: "radioatividade" e entender o fenômeno de emissão de luz, pois sem as limitações dos trabalhos dele, Marie Curie não teria espaço para pesquisar sobre o assunto. Como podemos perceber nas respostas da questão sobre a importância do "fracasso" de Becquerel:

Aluno 3" (...)Marie Curie pode se destacar apesar de ser mulher(...)";

Aluno 11"(...)Marie e Pierre levaram para um aprofundamento dos estudos(...)";

Aluno 10" (...)desencadeou a curiosidade da polonesa Marie Curie e seu esposo Pierre, que foi muito importante para as suas descobertas(...)";

\section{Aluno 7"(...)Se ele não tivesse fracassado eu não ia saber que Marie existia”.}

Se Marie Curie viu algo além de Becquerel foi por ter se apoiado naquilo que já existia sobre o assunto. Além disso, este é um excelente exemplo, pois conseguimos que os alunos abandonassem a seguinte visão de um aluno:

Aluno 3 "Os grandes cientistas do passado não se enganavam e já tinham chegado exatamente às ideias que nós aceitamos hoje em dia."

Nos relatos, obtidos principalmente das observações livres, é possível perceber que os alunos compreenderam que existia um grande volume de trabalhos sobre o assunto naquele período, que a descoberta da radioatividade poderia ter sido atribuída a qualquer outro cientista que foi citado nos textos.

Sendo assim, trabalhamos com os alunos que a radioatividade é um fenômeno natural que foi observado e compreendido e só mais tarde teríamos a radioatividade artificial, já que inicialmente havia a percepção da radioatividade ser algo "fabricado". Esta atividade, além de colaborar no trabalho da divulgação do progresso científico em um contexto histórico, estimulou uma postura proativa dos alunos ao terem que pesquisar, debater e serem questionados, sobre o trabalho do cientista e as dificuldades encontradas pelo contexto histórico em que estavam inseridos no momento em que viveram. É importante salientar sobre o interesse pela vida da cientista Marie Curie. Os alunos desenvolveram grande admiração por ela devido as dificuldades enfrentadas no meio social e científico.

\section{Considerações Finais}

A intervenção didática mostrou ter uma aplicabilidade muito simples, o que favorece o seu uso por diferentes professores em diferentes realidades, entretanto, isto não significa que 
esta aula seja um modelo sem nenhum tipo de falha, em uma sala de aula, a heterogeneidade é característica, ou seja, os pensamentos e as metodologias são diversas.

A partir dessa intervenção didática, apresentamos o tópico radioatividade, utilizando um recorte histórico de alguns cientistas em um período como um elemento motivador do processo de ensino/aprendizagem e, além disso, foi possível contribuir para que os estudantes pudessem ter a oportunidade de repensarem o conhecimento científico e assim, pudessem apresentar uma visão mais coerente sobre o trabalho do cientista, retirando-o de uma visão deformada que se apresenta "aproblemática" e "ahistórica".

Nessa perspectiva, as estratégias didáticas utilizadas conseguiram alcançar o que foi inicialmente pretendido com o objetivo, a proposta foi muito bem aceita, pois os próprios alunos reconheceram que até mesmo os cientistas tendem a observar o que foi previsto e, por vezes, ignoram aquilo que contraria sua previsão inicial.

A estratégia didática favoreceu a humanização do ambiente escolar, o trabalho em grupo, o diálogo entre os estudantes, a socialização das concepções alternativas referentes aos assuntos estudados, inclusive identificando semelhanças com visões históricas, a problematização, a argumentação, o trabalho com hipóteses, a comunicação em Química e, por fim, a aprendizagem de conceitos e temas científicos. Respeitando e levando em consideração as diferentes realidades existentes nas diferentes escolas e regiões do país, devemos considerar que para essa turma de alunos e para a realidade da escola em que a proposta foi aplicada, os resultados foram muito satisfatórios.

A partir das atividades desenvolvidas em sala, foi possível combater algumas concepções errôneas sobre Ciência e, ao mesmo tempo, aplicar uma sequência didática interdisciplinar utilizando a História da Ciência como base para o ensino do tópico proposto, a radioatividade.

\section{Referências}

ALVIM, M.H. E ZANOTELLO, M. História das ciências e educação científica em uma perspectiva discursiva: contribuições para a formação cidadã e reflexiva. Revista Brasileira de História da Ciência, Rio de Janeiro, v. 7, n. 2, p. 349-359, jul.-dez., 2014.

BARP, E. Contribuições da História da Ciência para o Ensino da Química: Uma Proposta para Trabalhar o Tópico Radioatividade. Revista História da Ciência e Ensino: Construindo Interfaces, São Paulo Volume 8, pp. 50-67, 2003.

BRASIL. Orientações curriculares para o ensino médio: Ciências da Natureza, Ministério da Educação. Secretaria de Educação Básica, vol. 2, Brasília, 2006. 
Res., Soc. Dev. 2019; 8(1):e4281674

ISSN 2525-3409 | DOI: http://dx.doi.org/10.33448/rsd-v8i1.674

FORATO, T. C. M. A natureza da ciência como saber escolar: um estudo caso a partir da história da luz. Tese (Doutorado em Educação). Universidade de São Paulo, São Paulo, 2009.

GIL, Antônio Carlos. Métodos e técnicas de pesquisa social. 5. ed. São Paulo: Atlas, 1999.

GIL PÉREZ, Daniel et al. Para uma imagem não deformada do trabalho científico. Ciência \&

Educação, v. 7, n. 2, p. 25-153, 2001.

IGNOTOFSKY, R. As Cientistas: 50 mulheres que mudaram o mundo, tradução de Sônia Augusto - São Paulo: Blucher, 2017.

LAKATOS, E.M; MARCONI, M. A. Fundamentos da metodologia científica. 7a ed. São Paulo: Atlas, 2010.

MARTINS, R. A. História e História da Ciência: encontros e desencontros. In: Actas do $\mathbf{1}^{\mathbf{0}}$ Congresso Luso-Brasileiro de História da Ciência e da Técnica. Évora: Centro de Estudos de História e

Filosofia da Ciência da Universidade de Évora, 2001. ., Como Becquerel não descobriu a radioatividade, Caderno Catarinense do

Ensino de Física. 7, Florianóplois, no especial (jun. 1990): 27-45.

MATHEUS, A. L. Química em questão, $1^{\text {a }}$ ed. São Paulo: Claro Enigma; Rio de Janeiro: Editora Fio Cruz, 2012.

PEDUZZI, L. O. Q.; Sobre a utilização didática da História da Ciência. In:PIETROCOLA, M. (Org).

Ensino de física: conteúdo, metodologia e epistemologia em uma concepção integrada. 2.ed.,

Florianópolis, Ed. Da UFSC, pp. 151-170, 2005.

SILVA, B. V. C. Controvérsias sobre a natureza da luz: uma aplicação didática. Dissertação de Mestrado. Tese (Mestrado em Ensino de Ciências e Matemática). Universidade Federal do Rio Grande do Norte, Natal, 2010.

.; História e Filosofia da Ciência como subsídio para elaborar estratégias didáticas em sala de aula: um relato de experiência em sala de aula. Revista Ciências \& Ideias, Rio de Janeiro, Volume 3, N.2 - Out./2011-Mar./2012. 